\title{
Review Article \\ Effect of Land Use and Climate Change on Runoff in the Dongjiang Basin of South China
}

\author{
Yanhu He, ${ }^{1,2}$ Kairong Lin, ${ }^{1,2}$ and Xiaohong Chen ${ }^{1,2}$ \\ ${ }^{1}$ Center for Water Resources and Environment, Sun Yat-Sen University, Guangzhou 510275, China \\ ${ }^{2}$ Key Laboratory of Water Cycle and Water Security in Southern China of Guangdong Higher Education Institutes, \\ Guangzhou 510275, China
}

Correspondence should be addressed to Xiaohong Chen; eescxh@mail.sysu.edu.cn

Received 15 February 2013; Revised 15 May 2013; Accepted 1 June 2013

Academic Editor: Yongping Li

Copyright (C) 2013 Yanhu He et al. This is an open access article distributed under the Creative Commons Attribution License, which permits unrestricted use, distribution, and reproduction in any medium, provided the original work is properly cited.

\begin{abstract}
Variability and availability of water resources under changing environment in a regional scale have been hot topics in recent years, due to the vulnerability of water resources associated with social and economic development. In this paper, four subbasins in the Dongjiang basin with a significant land use change were selected as case study. Runoffs of the four subbasins were simulated using the SCS monthly model to identify the quantitative impacts of land use and climate change. The results showed that (1), in the Dongjiang basin, temperature increased significantly, evaporation and sunlight decreased strongly, while precipitation showed a nonsignificant increase; (2) since the 1980s, land uses in the Dongjiang basin have experienced a significant change with a prominent increase in urban areas, a moderate increase in farmlands, and a great decrease in forest areas; (3) the SCS monthly model performed well in the four subbasins giving that the more significant land use change in each subbasin, the more runoff change correspondingly; (4) overall, runoff change was contributed half and half by climate change and human activities, respectively, in all the subbasins, in which about $20 \%$ 30\% change was contributed by land use change.
\end{abstract}

\section{Introduction}

Environment Change (including land use change and climate change) and its impacts on water resources have always been the hot issues in recent years. The direct or indirect impacts on the hydrological regime brought by land use and climate change both have contributed to some water problems, such as water shortage, flooding, and water logging to different extent. Some researches have been conducted to study the impacts of land use and climate change on water resources in different basins [1-5]. Particularly in the humid region of south China, six hydrological models were used to simulate the hydrological impact of some climate change scenarios, and response strategies for water supply and flood control due to climate change were analyzed in the Dongjiang basin by Jiang et al. [6]. South China has identified an increasing trend of extreme rainfall events, and the correlation between such events and flood events was studied by Fu et al. [7]. Climate change makes flooding more frequent in some regions $[8,9]$. Additionally, land use change also has notable impact on the hydrological cycle [10-12]. Overall, hydrological process and the variability and availability of water resources would change a lot due to land use change and climate change.

As the biggest developing country in the world, China has experienced an explosive economic growth over a couple of decades, which results in the prominent land use change. This change can alter evaporation patterns and potentially affect water resources in a region. The impacts of climate change on water resources and agriculture in China were analyzed by Piao et al. [13], and the results indicated that agriculture relying on the resultant increase in glacier runoff, especially in western China, would face a challenge, although its climate trends remained moderate compared to natural variability [13]. Even worse was the more frequent occurrence of drought and flood extremes largely due to climate change in different parts of China [14]. Some researches have focused on the variability of runoff in the Dongjiang basin under the impacts of climate change and human activities, especially land use change in recent decades [15]. Definitely, there is an increasingly serious challenge in the availability of water 
resources, and its exploitation and management will be more or less affected.

As to a basin, climate change and human activities both contribute to the hydrological cycle, and this finding has been supported by many studies [16-19]. Many studies have been carried out to distinguish the roles of land use and climate change on water resources. The approach to the calculation for the runoff change due to precipitation and potential evaporation was proposed [20-22]. Based on which, the separated impacts of human activities and climate change on natural runoff change in the Poyang basin from 1992 to 2000 were analyzed quantitatively by Ye et al. [23]. In recent years, much attention has been paid to analyze the separated quantitative effects of land use and climate change, and some progress has been made, although further research still needs to be carried out. A simple approach to distinguish land-use and climate-change effects on water resources was developed with a coupled water-energy budget analysis in US Midwest area by Tomer and Schilling [11]. Combined impacts of land cover and climate changes on hydrological processes of the Kejie watershed in the eastern Himalayas were assessed with a SWAT model, which revealed that land-cover change had more effects than those of climate change in the short and middle terms [24]. Furthermore, in many river basins of China, many studies have been conducted to assess the impacts of climate change and human activities on the runoff variation. As to Tarim River, the impact of human activities had increased the runoff with a ratio of $41 \% \sim 75 \%$ for different ages [25], and similar research can be found in the Wuding River [26]. In addition, some relative studies also took place in the Heihe catchment, Chaobai River, and Mian River basin [27-29], which came to a conclusion that climate change and human activities have the separated impacts on the runoff change varying from place to place. There is no exception for the Dongjiang basin [30]. However, few researches have been conducted to identify the quantitative effects of human activities and climate change on runoff in the study area. Moreover, most of the previous studies focused on a large scale basin and had no cases for comparison, which tends to limit our understanding of the impacts of climate change and human activities on water resources in the study area. The quantitative effect of land use change on runoff of the basin has not been revealed yet. Therefore, it is desirable to separate the impacts of climate change and human activities, specifically the land use change, on water resources under a changing environment in the study area.

Hydrological models have been widely used to study many practical and pressing issues that arise during planning, design, operation, and management of water resources systems [31, 32] and also to quantify the impacts of land use and climate change on the hydrological cycle. For example, a conceptual rainfall-runoff model was applied to the Rhine basin for the purpose of modeling the effect of land use change on the runoff. The results suggested that increased urbanization led to an increase in the lower peak runoff, compared to a considerable reduction of both the peak runoff and the total runoff volume resulted from intensified forestation [33]. Besides, the hydrological model considering other elements such as biogeochemistry was applied to reveal how land use change affects hydrological regimes at the watershed scale [34]. According to the available climate and hydrological data and the hydrological characteristics of the basin studied, many conceptual or distributed hydrological models were introduced to analyze the hydrological response under land use and climate change [35-38]. Trend analysis of climate variables is necessary to detect the variability of climate variables, such as temperature and precipitation $[39,40]$, which provides supports for study of the impacts on the hydrological cycle of land use change and climate change. Overall, hydrological model combined with statistic methods has been a prevalent and useful tool to clarify such an interesting phenomenon for a long time.

The Dongjiang River, which lies in south China, is an important fresh water source of the Pearl River Delta (one of the most developed areas in China). Specifically, it supplies $70 \%$ fresh water for Hong Kong. However, water shortage and water pollution in the Dongjiang basin appear to be more and more serious in recent years, due to the fast and persistent economic development and urbanization. Land use in this region has changed prominently since 1980s and contributed to hydrological response in the Dongjiang basin. Meanwhile, climate change under the global warming also plays an important role in the variation of hydrological processes. The combined effects of land use and climate changes lead to a series of conflicts between water use and water supply. In this paper, four sub-basins, the Shuntian, Lantang, Jiuzhou, and Yuecheng, within the Dongjiang basin are selected for study (Figure 1). Major climate variables were taken to trend analysis by using the Mann-Kendall test method, and runoffs in two different periods (natural and human activity periods) were simulated with the SCS monthly model for each basin. The aims of this study are to explore the temporal and spatial characteristics of land use change and climate variables in each sub-basin, to study the possible causes of the change, more specifically, to identify the roles played by land use change and climate change, as well as other human activities, on the runoff change, respectively. A comparison between the independent effect of land use and climate change in the four sub-basins will be conducted.

\section{Basic Knowledge and Data}

2.1. Study Area. The Dongjiang River (Figure 1) springs from Jiangxi Province and flows into the Pearl River estuary from northeast to southwest, which forms the Dongjiang basin. The Dongjiang basin is located between $113^{\circ} 52^{\prime}$ and $115^{\circ} 52^{\prime}$ $\mathrm{E}$ in longitude and $22^{\circ} 38^{\prime}$ and $25^{\circ} 14^{\prime} \mathrm{N}$ in latitude. This basin has a drainage area of $35,340 \mathrm{~km}^{2}$, about $90 \%$ of which is in Guangdong Province. The mainstream of the basin is about $562 \mathrm{~km}$ long with an average slope of about $0.039 \%$ [30].

The Dongjiang basin has a subtropical climate with a mean annual temperature of $21^{\circ} \mathrm{C}$. The annual rainfall over the basin varies between $1500 \mathrm{~mm}$ in the dry season from October to March and $2400 \mathrm{~mm}$ in the wet or monsoon season from April to September. The basin has some different soil types and the dominated type is alluvial, which is centered largely in the central and southern part of the basin. 


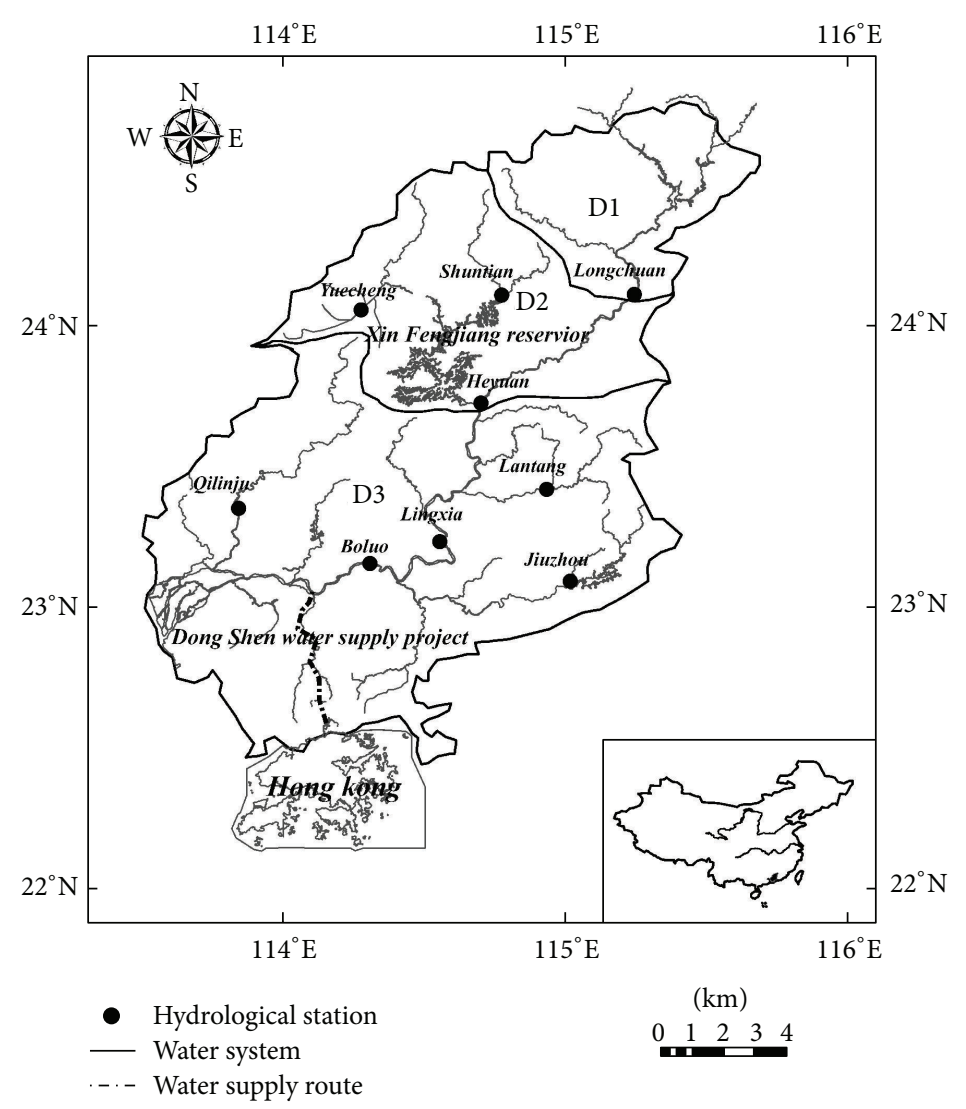

FIgure 1: The sketch map of the Dongjiang Basin.

The major land use type of this area is forest, although the urban area has extended year by year with the fast pace of urbanization since the 1980s. Locations of the four sub-basins are shown in Figure 1.

\subsection{Development of Economy and Society. The Dongjiang} basin has experienced a fast development of economy and society over the recent 30 years. Population and GDP (gross domestic product) of the three regions (Huizhou, Heyuan, and Dongguan) within the basin from 1980 were analyzed. Detailed information can be seen in Figure 4.

Population and economy in the three regions have kept a rapid and persistent development due to China's reform and opening policy. Refering to Figure 4, population of each region has been expanding rapidly since 1980. In which, population of Huizhou had increased from 1.92 million in 1980 to 3.6 million in 2006, with the average growth rate of $1.08 \%$. The GDP of each region also increased rapidly, especially Dongguan, whose GDP increased from 8 billion Chinese Yuan in 1980 to 262.7 billion Chinese Yuan in 2006 with the average growth rate of $14.34 \%$. There is no doubt that the growth of population and the development of economy depend largely on land resources. Therefore, we can infer that land use has changed greatly for decades in accordance with the social and economic development in the study area.
2.3. Data. The climatic data used in the study, including time series of annual average precipitation, evaporation, and temperature from 1956 to 2008 of the 21 meteorological stations in the Dongjiang basin, was provided by the Guangdong Meteorological Bureau. The monthly runoff time series for 4 hydrological stations (Shuntian, Lantang, Jiuzhou, and Yuecheng) from 1970 to 2008 were acquired from Hydrological Bureau of Guangdong Province. The daily precipitation, evaporation, and runoff time series of the main rainfall and hydrological stations in the Dongjiang basin from 1970 to 1978 were extracted from Water Conservancy and Electric Power Bureau of Guangdong Province.

Two multitemporal satellite sensor images, Landsat Thematic Mapper (TM) imagery of the 1980s and 2000s, were downloaded from Global Land Cover Facility. Based on the images, two periods (1980s and 2000s) of land use and vegetation cover maps of the Dongjiang basin (Figure 2) were gained with the ArcGIS spatial analysis technique. A digital elevation model (DEM) with a spatial resolution of $30 \mathrm{~m}$ and soil type data with a spatial resolution of $90 \mathrm{~m}$ (Figure 3) of the Dongjiang basin were downloaded from China Soil Scientific Database (CSSD) and CGIAR-CSI, respectively.

\section{Methodologies}

3.1. Mann-Kendall Test for Time-Series Trend. Developed by Mann and later improved by Kendall [41, 42], highly 


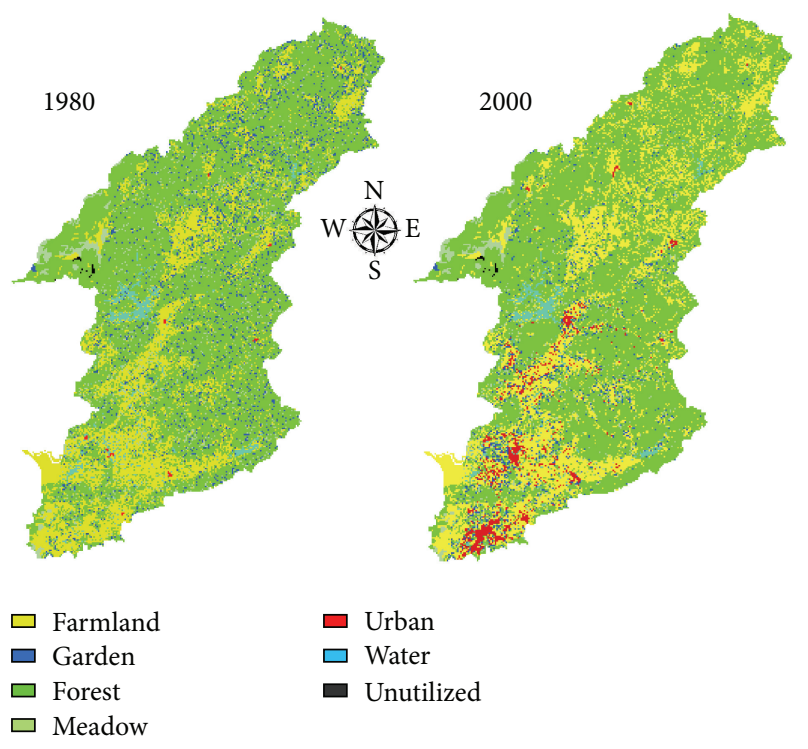

Figure 2: Land uses of two periods (1980 and 2000) in the Dongjiang basin.

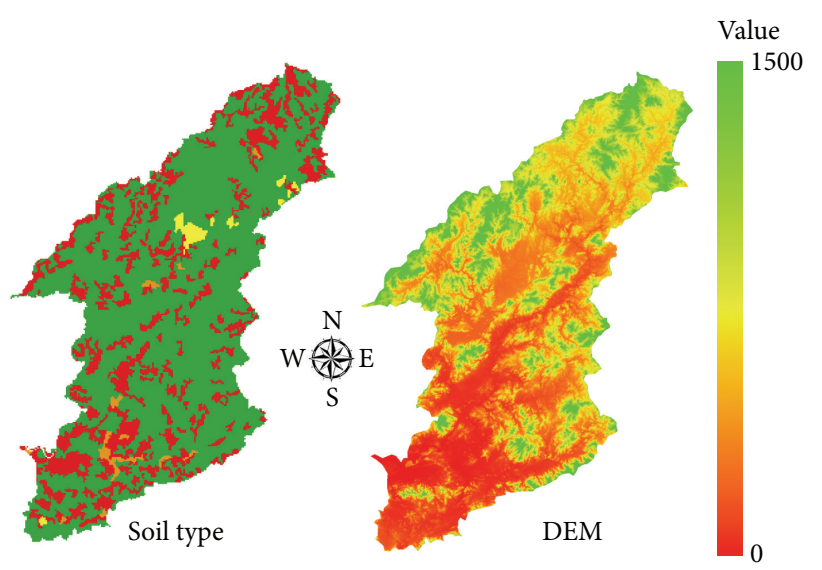

Minimum infiltration rate $(\mathrm{mm} / \mathrm{h})$

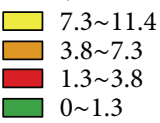

FIgURE 3: Soil type and DEM of the Dongjiang basin.

recommended for general use by the World Meteorological Organization [43], the Mann-Kendall test was widely used to detect time-series trends in hydrological and climatic data in many researches. The Mann-Kendall test has some advantages including its simplicity, ability to deal with nonnormal and missing data distributions, and robustness to the effects of outliers and gross data errors [44-46].

Firstly, the Mann-Kendall test defined a variable $S$ as:

$$
S=\sum_{k=1}^{n-1} \sum_{j=k+1}^{n} \operatorname{sgn}\left(x_{i}-x_{j}\right) \text {. }
$$

Then the presence of a statistically significant trend is evaluated using the $Z$ value:

$$
Z= \begin{cases}\frac{S-1}{\sqrt{\operatorname{Var}(S)}}, & S>0 \\ 0, & S=0 \\ \frac{S+1}{\sqrt{\operatorname{Var}(S)}}, & S<0 .\end{cases}
$$

Besides, the standard normal cumulative distribution function $F_{n}$ under the significance level $\alpha$ is given by $F_{n}\left(Z_{\alpha} / 2\right)=\alpha / 2$. If $|Z|>Z_{\alpha} / 2$, the hypothesis of $H_{1}$ for a two-sided test can be accepted. Positive value $Z$ indicates an upward trend while negative value a downward trend. More descriptions of this method can be found in many researches [47-49]. In this paper, trend analysis of climatic variables and runoff in the Dongjiang basin were conducted with the Mann-Kendall test based on over 50 years of climatic and hydrological data.

In addition, mutation detections of the climatic data were also conducted by the Mann-Kendall mutation analysis test method; a statistic variable of this method is

$$
\begin{gathered}
S_{K}=\sum_{i=1}^{k} r_{i}, \quad k=2,3, \ldots, n, \\
r_{i}= \begin{cases}+1, & x_{i}>x_{j}, \quad j=1,2, \ldots, i, \\
0, & x_{i} \leq x_{j},\end{cases}
\end{gathered}
$$

where $S_{K}$ is the counts for the $x$ series when $x_{i}$ is greater than $x_{j}$.

$U F_{K}$ is the standard normal distribution and can be calculated based on the $x$ series:

$$
U F_{K}=\frac{\left[S_{K}-E\left(S_{K}\right)\right]}{\sqrt{\operatorname{var}\left(S_{K}\right)}}, \quad k=1,2 \ldots, n,
$$

where $U F_{1}=0, E\left(S_{K}\right)$ and $\operatorname{var}\left(S_{K}\right)$ are the expected value and variance of $S_{K}$ which can be calculated on condition that the $x$ series is mutually independent with the same continuous distribution:

$$
\begin{gathered}
E\left(S_{K}\right)=\frac{n(n+1)}{4}, \\
\operatorname{var}\left(S_{K}\right)=\frac{n(n-1)(2 n+5)}{72} .
\end{gathered}
$$

3.2. SCS Rainfall-Runoff Model. Developed by the Soil Conservation Service of U.S. Department of Agriculture (USDA) early in 1954, the SCS model is widely used in the USA and many other countries [50,51]. Several advantages of this model are as follows: (1) the characteristics of the land cover such as soil, slope, vegetation and land use in a basin can be considered with the SCS model; the possible change on the rainfall-runoff relationship can be preliminarily estimated according to the change of land use, and (2) it has the advantages of simplicity in structure and convenience in use with very low dependence on data. 

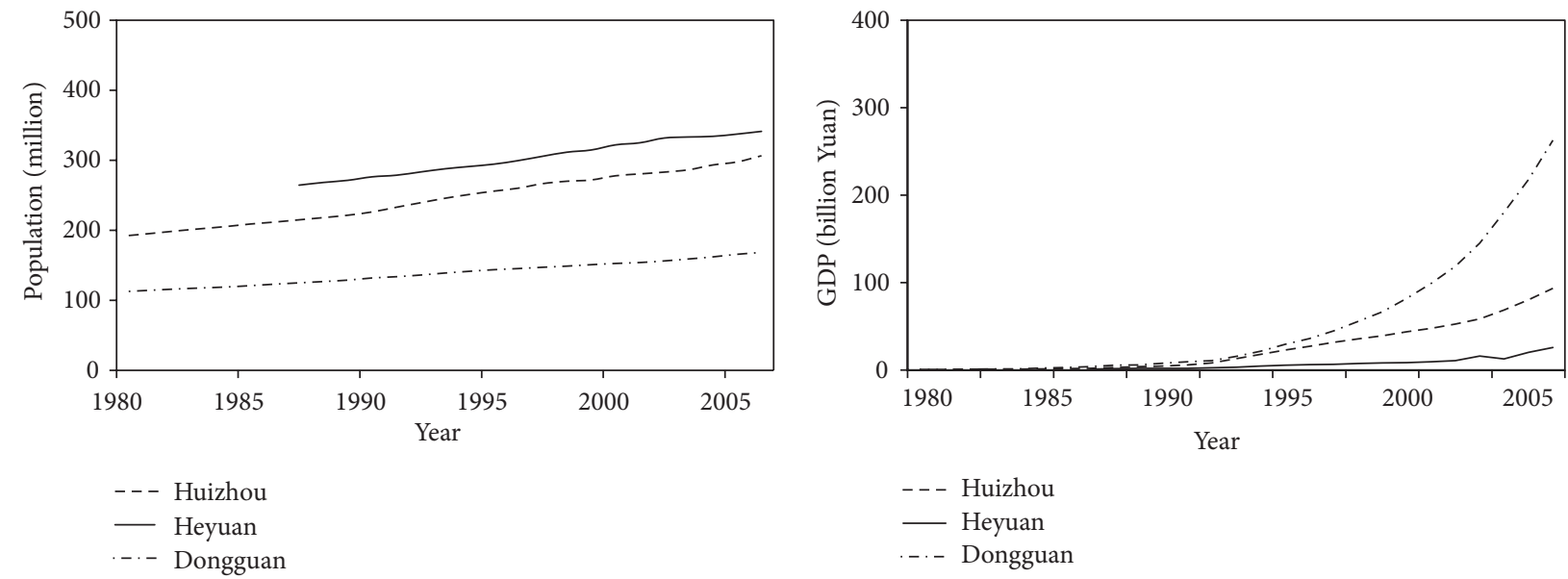

FIGURE 4: Sketch map of economic and social development in the Dongjiang basin.

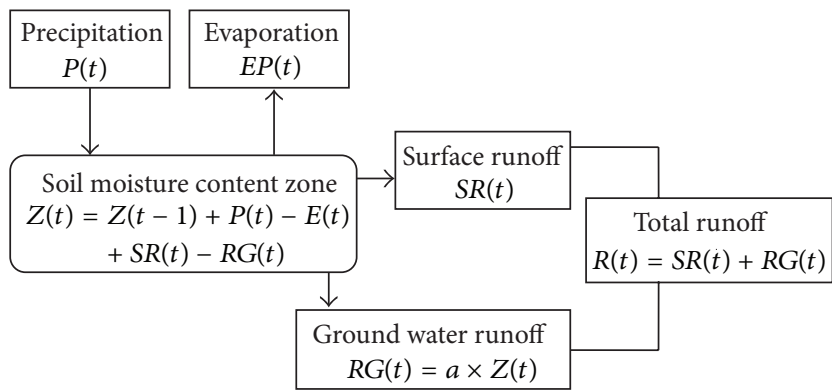

FIGURE 5: A schematic diagram of the water balance in a basin.

The runoff yield for the SCS model is

$$
R= \begin{cases}\frac{\left(P-I_{a}\right)^{2}}{P+S-I_{a}}, & P \geq I_{a}, \\ 0, & P<I_{a},\end{cases}
$$

where $R$ is the runoff, $P$ is the precipitation, $I_{a}$ is the initial loss, and $S$ is the present probable maximum retention in the basin which is the top limit of the later loss.

Initial loss $I_{a}$ can be calculated by an empirical correlation with $S$ :

$$
I_{a}=\alpha S
$$

where $\alpha$ is the coefficient of the initial losses which is related to the initial soil water content of the basin.

To eliminate the large variation scope of the $S$ value, there is an empirical relation for $\mathrm{CN}$ (a non dimensional parameter) and $S$ :

$$
S=\frac{25400}{C N}-254
$$

The curve number $\mathrm{CN}$ is a key and comprehensive parameter within SCS model. CN describes the watershed features before a rain and is affected by AMC (antecedent moisture condition), slope, vegetation, soil type, and land use condition with a value of $0 \sim 100$. AMC can be divided into 3 classes: AMC I-arid condition, AMC II-normal condition, and $A M C$ III-moist condition. The specific basis for the classification and the estimation of the $\mathrm{CN}$ value can be found in related references [52].

Input by the observed monthly precipitation and evaporation, the SCS model yields the monthly runoff. A key issue here is to calculate the actual evaporation by using the SCS monthly model. Based on the research results from the twoparameter monthly water balance model [53], the monthly actual evaporation can be calculated by

$$
E(t)=C \times E P(t) \times \tanh \left(\frac{P(t)}{E P(t)}\right),
$$

where $E(t)$ is the actual monthly evaporation, $E P(t)$ is the observed evaporation from the evaporating dish, $P(t)$ is the monthly precipitation, and $C$ is one of the parameters in the model (nondimensional).

The total discharge consists of two parts: the surface flow $(S R(t))$ and the baseflow $(R G(t)) . S R(t)$ can be gained by (6), while $R G(t)$ can be calculated with

$$
R G(t)=a \times Z(t)
$$

where $a$ is the coefficient of the groundwater flow and $Z(t)$ is the soil moisture content which can be calculated by

$$
Z(t)=Z(t-1)+P(t)-E(t)+S R(t)-R G(t) .
$$

A schematic diagram for the water balance in a basin is shown in Figure 5. The SCS model is used to simulate the monthly runoff process in this study. There are two parameters, $C$ and $\alpha$, in the model.

3.3. Approach to Distinguish the Respective Impact of Land Use and Climate Change to Water Resources. The total runoff change can be obtained by the difference between the observed runoffs in two different periods, respectively, that is, the intensive human activities period and the low human activities period (natural condition). It is assumed that the 


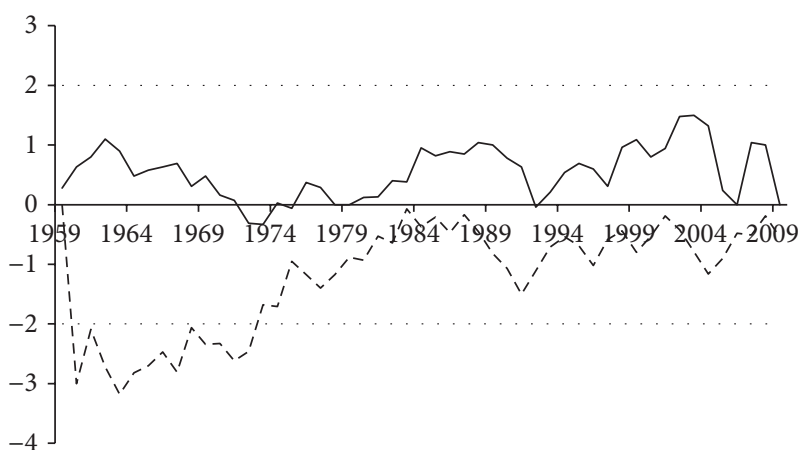

(a) Precipitation

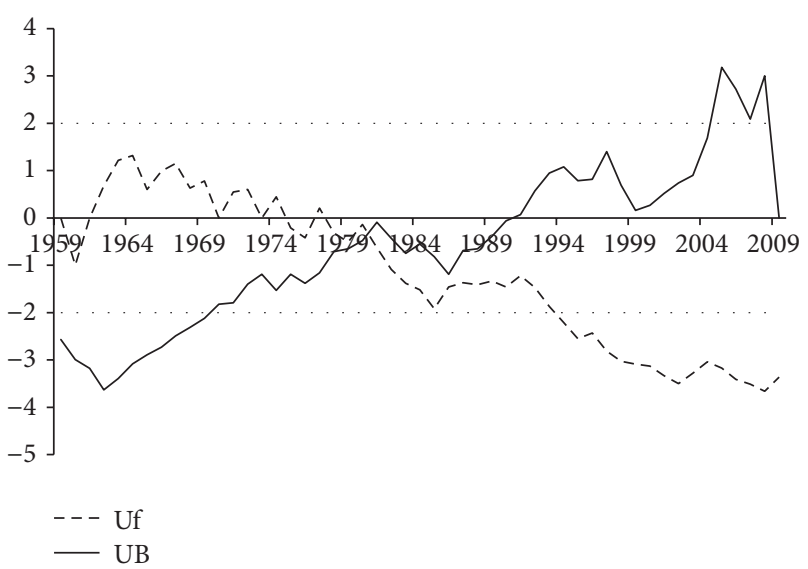

(c) Sunlight

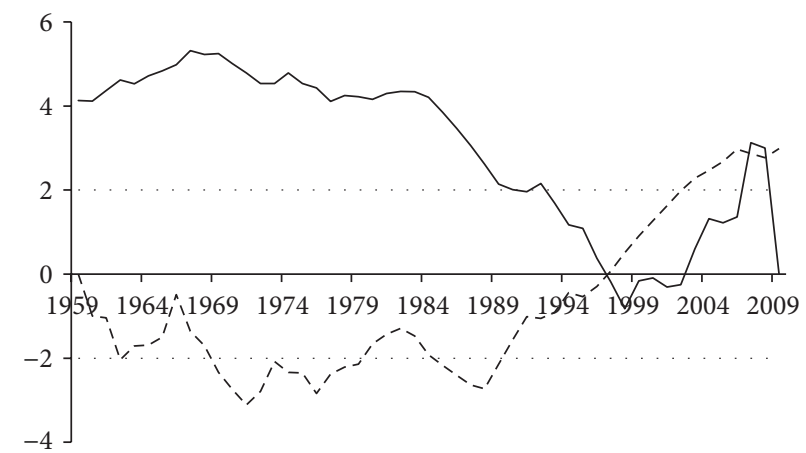

(b) Temperature

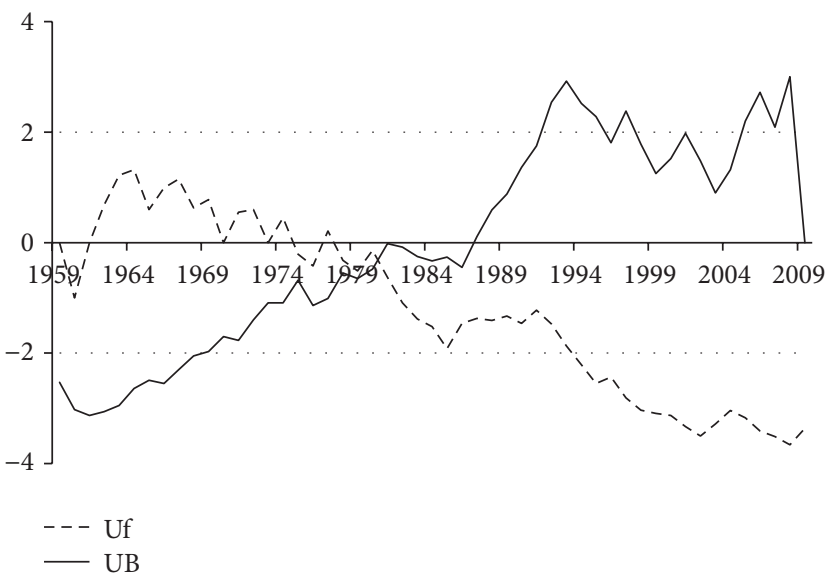

(d) Evaporation

Figure 6: Mann-Kendall test trend of four meteorological elements in the Dongjing basin.

runoff change in the low human activities period is affected only by climate change.

Therefore, the impacts of climate change, land use change, and other human activities on runoff change can be separated according to the following calculations:

$$
\begin{gathered}
\Delta R_{L}=R_{H 2}-R_{H 1}, \\
\Delta R_{C}=R_{B}-R_{H 1}, \\
\Delta R_{0}=\Delta R_{T}-\Delta R_{C}-\Delta R_{L}, \\
\Delta=\left|\Delta R_{0}\right|+\left|\Delta R_{C}\right|+\left|\Delta R_{L}\right|, \\
\mu L=\frac{\left|\Delta R_{L}\right|}{\Delta} \times 100 \%, \\
\mu C=\frac{\left|\Delta R_{C}\right|}{\Delta} \times 100 \%, \\
\mu R_{0}=\frac{\left|\Delta R_{0}\right|}{\Delta} \times 100 \%,
\end{gathered}
$$

where $\Delta R_{L}$ is the runoff change due to land use change, from time period of phase I to phase II; $R_{H 2}$ and $R_{H 1}$ are the simulated runoffs corresponding to the land uses of phase II and phase I, respectively, and both of them can be calculated with the SCS monthly model; $\Delta R_{C}$ is the runoff change caused by climate change; $R_{B}$ is the natural runoff of phase I; $\Delta R_{T}$ is the total runoff change; $\Delta R_{0}$ is the runoff change due to other human activities except for land use change; $\mu L, \mu C$, and $\mu R_{0}$ are the percentages for the roles played by land use change, climate change, and other human activities, respectively.

\section{Results and Discussion}

4.1. Time-Series Analysis. The variation trends of the climatic variables over 50 years in the study basin were analyzed with the linear regression and Mann-Kendall trend test method. Table 1 listed the detailed results obtained by the MannKendall trend test method. Figure 6 demonstrated the results for mutation analysis with the Mann-Kendall trend test and the linear regression method, respectively.

It can be seen from Table 1 that each climatic variable showed different degree of change in the Dongjiang basin during the past 50 years (1959-2008), according to its statistics by the Mann-Kendall trend test method. Precipitation showed a nonsignificant increasing trend $(M=0.22)$ at $99 \%$ confidence level, which is largely due to local atmospheric circulation and topography. Temperature in the same period showed a significant increasing trend $(M=3.34)$. While sunlight showed a significant decreasing trend. Meanwhile, very fast urbanization caused quick increase of impervious 
TABLE 1: M-K trend analysis for meteorological elements in the Dongjiang basin (1958-2009).

\begin{tabular}{|c|c|c|c|c|c|}
\hline \multirow[b]{2}{*}{ Statistics } & \multicolumn{5}{|c|}{ Meteorological elements } \\
\hline & $\begin{array}{c}\text { Precipitation } \\
(\mathrm{mm})\end{array}$ & $\begin{array}{c}\text { Temperature } \\
\left({ }^{\circ} \mathrm{C}\right)\end{array}$ & $\begin{array}{c}\text { Evaporation } \\
(\mathrm{mm})\end{array}$ & $\begin{array}{c}\text { Humidity } \\
\left(\mathrm{g} / \mathrm{m}^{3}\right)\end{array}$ & $\begin{array}{c}\text { Sunlight } \\
\text { (h) }\end{array}$ \\
\hline$\overline{\bar{C}}$ & 1852.92 & 21.30 & 1572.4 & 78.1 & 1813 \\
\hline$C_{v}$ & 0.16 & 0.02 & 0.05 & 0.03 & 0.09 \\
\hline$C_{s}$ & 0.13 & 0.56 & 0.50 & -0.94 & 0.45 \\
\hline$M$ & 0.22 & 3.34 & -2.94 & -2.97 & -4.18 \\
\hline
\end{tabular}

area in the study basin in the last 50 years. These all contributed to a decreasing trend of evaporation. Temperature showed an increasing trend with a distinct mutation taking place around 1997, and sunlight and evaporation both had an abrupt change in 1982. Overall, the change of climatic variables in the Dongjiang basin during the past 50 years was significant.

It can be found from the $C_{v}$ value of each climatic variable that there was a significant internal variation for precipitation but not for temperature. It can be illustrated by both the rainfall pattern and the atmospheric circulation in the study area: Dongjiang basin is located in the southern humid region in China and deeply affected by the monsoon circulation with the rainfall patterns of frontal rain and convectional rain. Therefore, the internal variation of precipitation is significant.

To clarify the relations among each climatic variable and the runoff, the correlation coefficients and relevancies were analyzed. According to the spatial differences of land cover and climatic variables, the Dongjiang basin was divided into three parts: the upper part centered with Longchuan, marked D1; the middle part centered with Heyuan, marked D2; and the whole basin centered with Boluo, marked D3. Tables 2 and 3 listed the correlation coefficients and relevancies, respectively. It can be seen from Table 2 that precipitation was positively related to runoff, and their correlation coefficient was the largest, which revealed that runoff in the Dongjiang basin depended mainly on precipitation. In contrast, temperature, sunlight, and evaporation were negatively related to runoff. Among the three parts of the basin, the correlation coefficient of precipitation and runoff in D2 was the least. The reason was that there located the biggest reservoir, the Xinfengjiang Reservoir (Figure 1) in D2. In addition, more than 20 middle and small sized reservoirs and hydraulic projects were constructed in the same period, which made a more significant change of land cover as compared to D1 and D3. Actually, runoff in D2 is mainly controlled by regulation of the reservoir, so precipitation was less correlation with runoff in D2. Table 3 showed that the relevancy between precipitation and runoff was the largest, indicating that precipitation was the major driver for runoff change in the whole study basin, which is similar to the results of correlation analysis.

4.2. Land Use Change Analysis. It has been found that the urban land and farmland increased in the study area [54]. Based on the raster graphics for land use of two periods (1980 and 2000), temporal and spatial variations of land use change in the Dongjiang basin were analyzed with the ArcGIS spatial analysis technique. Figure 2 showed the maps of land use in 1980 and 2000, respectively. Table 4 depicted the detailed information of the land use change in the form of a comparison.

It can be seen from Figure 2 that the dominant land uses in the study area, in 1980, were mainly forest (widely distributed in the whole basin) and farmland (mainly distributed in the upper basin), accounting for $64.56 \%$ and $22.33 \%$, respectively. while garden, meadow, and water took a little part with the percentage of $5.94 \%, 4.71 \%$, and $2.28 \%$, respectively. Urban land mainly distributed in the downstream basin, and the unutilized land took the least percentage in the Dongjiang basin. The area of two types of land use, urban land and farmland, increased from 1980, along with the decrease of garden $(2.65 \%)$, meadow $(1.23 \%)$, water $(0.49 \%)$, and forest $(2.38 \%)$ in 2000 , while the dominant land use was still forest in 2000. In all, since 1980s, the land use in the Dongjiang basin has been characterized with a prominent increase in urban land, a little increase in farmland, and great decrease in forest area, while little change in water area and unutilized land. This land use change due to fast social and economic development had a significant impact on the hydrological response and then contributed to the variability of water resources in the region.

\subsection{Runoff Simulation and Runoff Change Analysis}

4.3.1. The Value of $C N$. CN (curve number) can reflect the capacity of runoff yield for the land cover with a continuous spatial distribution. The $\mathrm{CN}$ isocline represents the runoff yield capacities in the study basin.

Based on land use maps of two periods (1980 and 2000) and soil type data of the Dongjiang basin, $\mathrm{CN}$ distribution maps (see Figure 7) of 3 AMC (antecedent moisture condition) scenarios in the same periods were obtained with spatial interpolation. Figure 8 showed the $\mathrm{CN}$ distribution maps for AMC II of the four sub-basins in the two periods.

4.3.2. Model Calibration and Validation. The SCS monthly model was calibrated in the period of 1970-1976 with climatic data and then validated in the period of $1977-1978$ by manual calibration method with the acceptable set of parameters after $\mathrm{CN}$ value analysis. To measure the performance of the model, we chose Nash-Sutcliffe coefficient of efficiency (NSE) criterion [55] and relative error (RE) as objective function. 
TABLE 2: The correlation coefficient of each meteorological element to runoff in the Dongjiang basin.

\begin{tabular}{|c|c|c|c|c|c|c|c|}
\hline Basin units & Basin scope & Gauge stations & Temperature & Precipitation & Evaporation & Sunlight & Humidity \\
\hline $\mathrm{D} 1$ & Upper & Longchuan & -0.10 & 0.80 & -0.4 & -0.35 & 0.27 \\
\hline D2 & Midstream & Heyuan & -0.23 & 0.69 & -0.28 & -0.39 & 0.35 \\
\hline $\mathrm{D}$ & The whole Basin & Boluo & -0.08 & 0.88 & -0.54 & -0.57 & 0.26 \\
\hline
\end{tabular}

TABLE 3: The relevancies between each meteorological element and runoff in the Dongjiang basin.

\begin{tabular}{|c|c|c|c|c|c|c|c|}
\hline Basin units & Basin scope & Gauge stations & Temperature & Precipitation & Evaporation & Sunlight & Humidity \\
\hline \multirow{2}{*}{ D1 } & \multirow{2}{*}{ Upper } & Longchuan & 0.4884 & 0.5503 & 0.4688 & 0.449 & 0.4702 \\
\hline & & Rank & 2 & 1 & 4 & 5 & 3 \\
\hline \multirow{2}{*}{$\mathrm{D} 2$} & \multirow{2}{*}{ Midstream } & Heyuan & 0.4857 & 0.5389 & 0.4659 & 0.4313 & 0.4861 \\
\hline & & Rank & 3 & 1 & 4 & 5 & 2 \\
\hline \multirow{2}{*}{$\mathrm{D}$} & \multirow{2}{*}{ The whole basin } & Boluo & 0.525 & 0.5968 & 0.4883 & 0.4495 & 0.5239 \\
\hline & & Rank & 2 & 1 & 4 & 5 & 3 \\
\hline
\end{tabular}

TABLE 4: Comparison of land use in the Dongjiang basin during two different periods.

\begin{tabular}{|c|c|c|c|c|c|c|}
\hline \multirow{2}{*}{ Land use } & \multicolumn{2}{|c|}{ The year 1980} & \multicolumn{2}{|c|}{ The year 2000} & \multirow{2}{*}{$\Delta_{\text {area }}\left(\mathrm{km}^{2}\right)$} & \multirow{2}{*}{ Ratio (\%) } \\
\hline & Area $\left(\mathrm{km}^{2}\right)$ & Ratio (\%) & Area $\left(\mathrm{km}^{2}\right)$ & Ratio (\%) & & \\
\hline Farmland & 6083.49 & 22.33 & 7272.73 & 26.69 & 1189.24 & 4.36 \\
\hline Garden & 1619.14 & 5.94 & 896.70 & 3.29 & -722.44 & -2.65 \\
\hline Forest & 17586.88 & 64.56 & 16939.87 & 62.18 & -647.01 & -2.38 \\
\hline Meadow & 1282.74 & 4.71 & 947.14 & 3.48 & -335.60 & -1.23 \\
\hline Built-up & 30.02 & 0.12 & 682.25 & 2.5 & 652.23 & 2.38 \\
\hline Waters & 619.99 & 2.28 & 480.12 & 1.79 & -139.87 & -0.49 \\
\hline Unutilized land & 17.38 & 0.06 & 20.80 & 0.07 & 3.42 & 0.01 \\
\hline
\end{tabular}
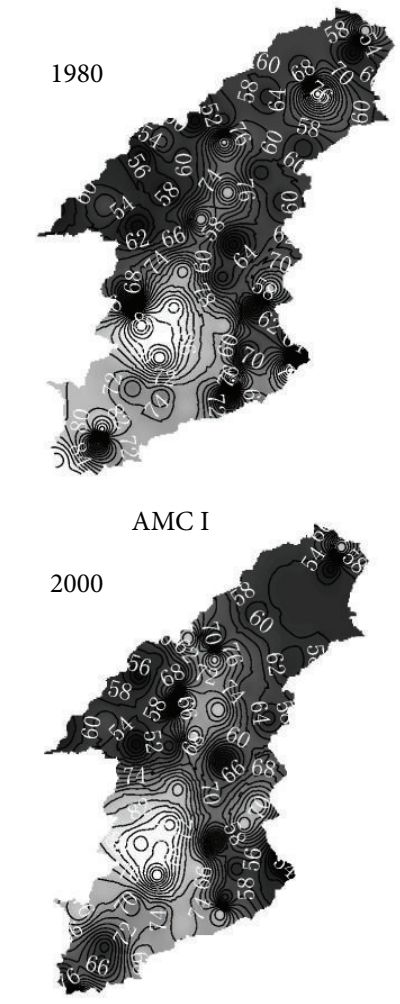
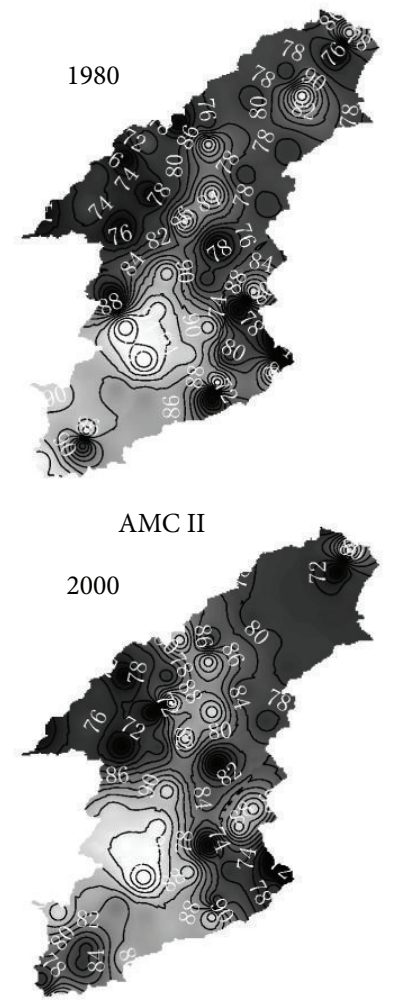
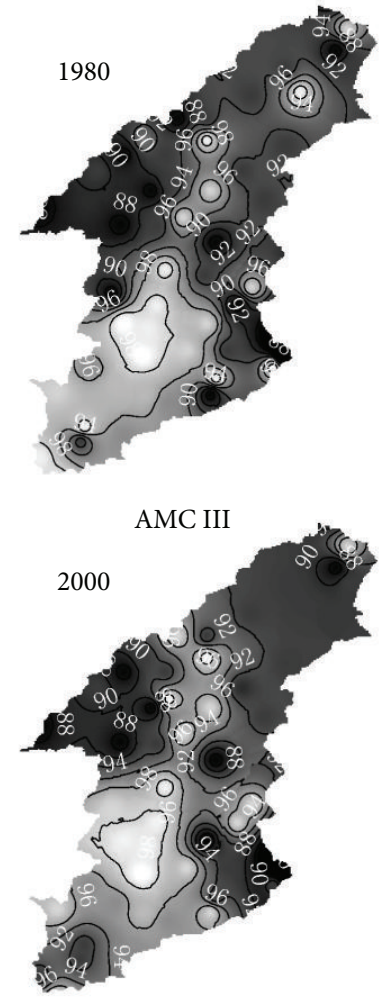

Figure 7: Comparison of CN distribution under 3 AMC scenarios in the Dongjiang basin of two periods (1980 and 2000). 
TABLE 5: Calibration and validation of the SCS monthly model.

\begin{tabular}{|c|c|c|c|c|c|c|c|c|c|}
\hline \multirow{2}{*}{ Sub-basins } & \multirow{2}{*}{ Runoff coefficient } & \multicolumn{3}{|c|}{ Calibration } & \multirow{2}{*}{ NSE/\% } & \multirow{2}{*}{$\mathrm{RE} / \%$} & \multicolumn{3}{|c|}{ Evaluation } \\
\hline & & Data length/years & $a$ & $c$ & & & Data length/years & NSE $/ \%$ & $\mathrm{RE} / \%$ \\
\hline Shuntian & 0.596 & 7 & 0.699 & 0.858 & 81.6 & 1.0 & 2 & 92.5 & -9.7 \\
\hline Yuecheng & 0.658 & 7 & 0.592 & 0.604 & 84.0 & 0.9 & 2 & 86.0 & 11.1 \\
\hline Lantang & 0.515 & 7 & 0.601 & 0.832 & 83.0 & 1.6 & 2 & 94.0 & -1.8 \\
\hline Jiuzhou & 0.571 & 7 & 0.674 & 0.821 & 82.3 & -0.5 & 2 & 79.3 & 20.9 \\
\hline
\end{tabular}

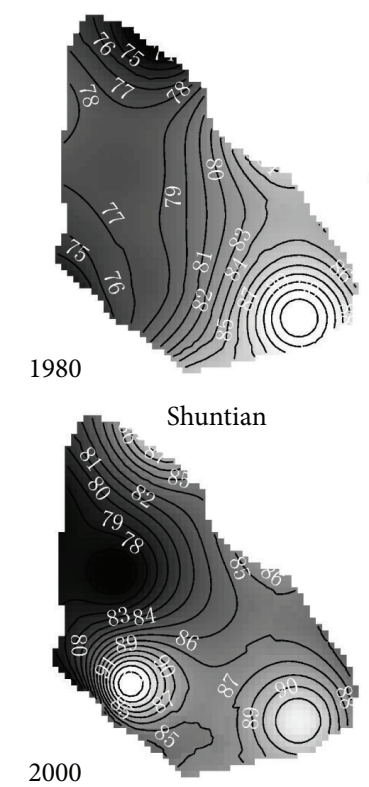

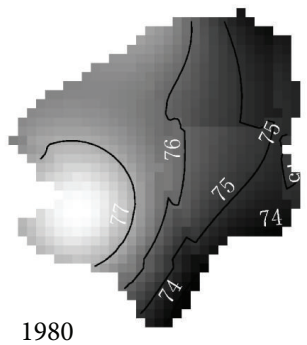

1980

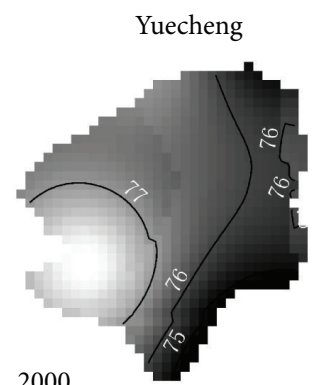

2000

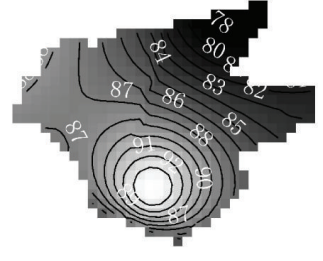

1980

Jiuzhou

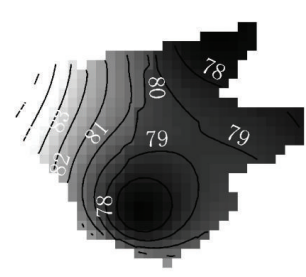

2000

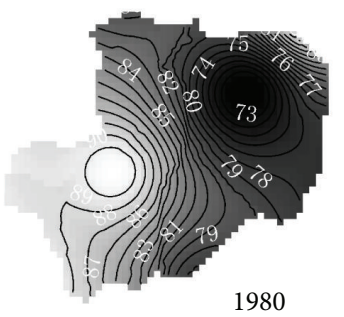

Lantang

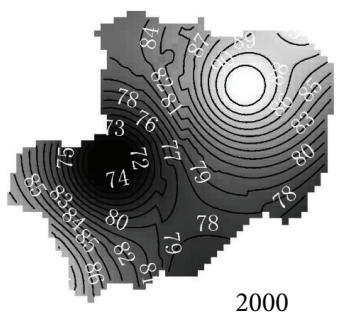

FIgURE 8: Comparison of the CN distribution under AMC II scenario for the four sub-basins in the Dongjiang basin of two periods (1980 and 2000).

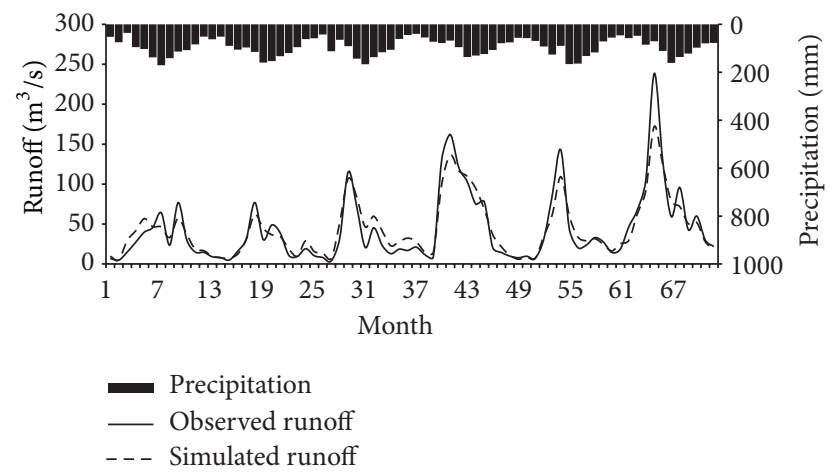

FIGURE 9: Comparison of simulated and observed runoffs in the calibration period (1970-1976) in the Shuntian subbasin.

The results of simulation were listed in Table 5. The comparisons between simulated and observed runoffs of the calibration and validation periods in Shuntian subbasin were illustrated in Figures 9 and 10, respectively. The simulated results by the SCS monthly model were comparable with the observations in the four sub-basins. Nash-Sutcliffe coefficients were above 0.8 , and RE was within the pale of 0.02 for those all four sub-basins in the calibration period. It can be inferred from Figures 9 and 10 that the simulated hydrograph

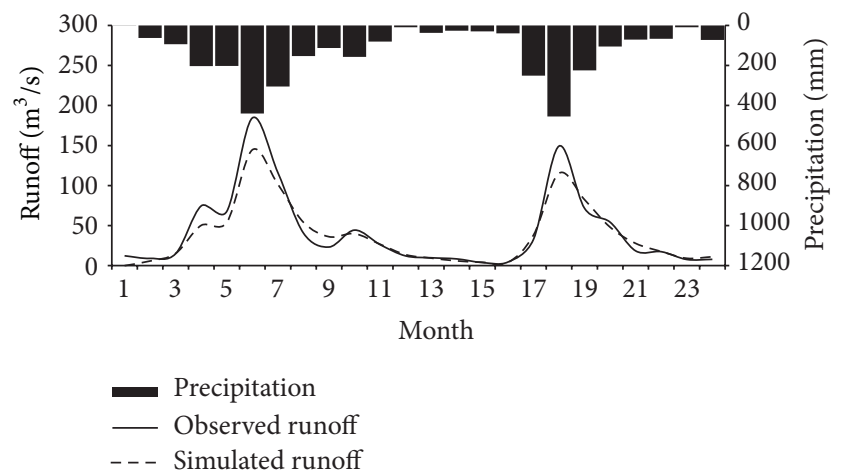

FIGURE 10: Comparison of simulated and observed runoffs in the validation period (1977-1978) in the Shuntian sub-basin.

matched well with the observed one, and the peak flows were coincided in both the calibration and validation periods. Overall, model performance was acceptable within the study domain, and reliable to be extended to reconstruct the natural runoff.

4.3.3. Runoff Simulation in Human Activity Period. Based on the CN value of land use in the first phase (before 1980) 
TABLE 6: Monthly runoff changes of natural and human activity periods in the four sub-basins $\left(10^{8} \mathrm{~m}^{3}\right)$.

\begin{tabular}{lcccccccccc}
\hline & & & \multicolumn{4}{c}{ Human activity period } \\
Sub-basin & Natural period $R_{N}$ & $R_{\mathrm{HR}}$ & $\Delta R_{T}$ & \multicolumn{2}{c}{ Land use change } & \multicolumn{2}{c}{ Climate change } & \multicolumn{2}{c}{ Other human activities } \\
& & & & $\Delta R_{L}$ & $\mu L(\%)$ & $\Delta R_{C}$ & $\mu C(\%)$ & $\Delta R_{0}$ & $\mu R_{0}(\%)$ \\
\hline Shuntian & 1.12 & 1.16 & 0.04 & 0.08 & 24.11 & -0.15 & 44.60 & 0.11 & 31.29 \\
Yuecheng & 0.55 & 0.53 & -0.01 & 0.03 & 19.54 & -0.08 & 54.74 & 0.04 & 25.72 \\
Lantang & 0.73 & 0.77 & 0.03 & 0.05 & 29.94 & -0.07 & 40.51 & 0.05 & 29.55 \\
Jiuzhou & 0.34 & 0.34 & -0.01 & 0.02 & 25.50 & -0.05 & 53.22 & 0.02 & 21.27 \\
\hline
\end{tabular}

and climatic data in the second phase (precipitation and evaporation, from 1980 to 2000) in the four sub-basins, the natural monthly runoff I and its process in the human activity period were simulated by using the SCS monthly model. And the monthly runoff II was obtained under the land use change condition (with the CN value of land use in 2000 as its input) by the same method. The difference between the simulated runoffs in the two phases was the runoff change due to land use change.

The simulated monthly runoff change due to land use change from 1980 to 2000 for each sub-basin was shown in Figure 11. It can be found that the runoff change varied from sub-basin to sub-basin, and the changes in Yuecheng sub-basin and Jiuzhou sub-basin were less than those of in Shuntian and Lantang, which was relevant to the variation scope of the $\mathrm{CN}$ value in the basins.

\subsubsection{The Quantitative Effect due to Climate and Land Use} Changes. The analysis of quantitative impacts on runoff due to human activities particularly land use and climate changes was carried out in the four sub-basins. The runoff change due to land use change was obtained from the simulated runoff by the SCS model in the two periods (human activity and natural periods). The quantitative impacts of climate change and human activities were identified by the method presented in (12), and the results were shown in Table 6.

It can be seen from Table 6 that, take Shuntian sub-basin, for instance, as compared to natural period, the runoff in human activity period increased by $4 \times 10^{6} \mathrm{~m}^{3}$. The $24.11 \%$ increase of runoff was contributed by the land use change. On the contrary, climate change contributed the $44.6 \%$ decrease to runoff, which was superior to that of land use change. A meaningful clue has been found for explaining such a result: as two most important factors of the runoff change, precipitation showed an insignificant increasing trend, which was different from that of temperature (significant increasing trend), and the compound effects led to the reduction of the total runoff. Other factors including natural and human aspects accounted for $31.29 \%$ to the runoff change. Overall, all the driving factors can make the runoff change to a different level among which the role played by climate change took nearly the half for each sub-basin. This was in accordance with the result of identifying the quantitative effect of land use and climate change on runoff in the high flow period in the Dongjiang basin [30].

The impact of land use change on the total runoff change in Lantang sub-basin was the highest (29.94\%) among the four sub-basins, while the impact ratios of climate change and other human activities were $40.51 \%$ and $29.55 \%$, respectively. In summary, human activities contributed $59.49 \%$ to runoff change, which revealed that human activities were the major driver for runoff change.

It was obvious that climate change with increased precipitation and decreased evaporation caused the increase of runoff in the study area. Furthermore, changes of innerannual distribution precipitation also affected the runoff change. Seven pairs of simulated runoff under nearly equal amount of precipitation were shown in Table 7. It can be found from Table 7 that the greater the percentage of precipitation in flood season, the greater the simulated runoff in Shuntian sub-basin, except for 1985 and 1987. It was also implied that precipitation was the major driver for runoff change in Shuntian sub-basin.

To analyze the impact of land use change, we divided annual precipitation into four classes as under $1500 \mathrm{~mm}$, $1500-1800 \mathrm{~mm}, 1800-2000 \mathrm{~mm}$, and above $2000 \mathrm{~mm}$ in the four sub-basins. The total runoff change due to land use change in each class was shown in Figure 12. It can be found that under larger precipitation, the runoff (to be flattened) of flood season was less as compared with that of drought season and the whole year in the four sub-basins. This was attributed to land cover conversion due to construction of reservoirs, which stored much water in flood season for flood prevention and water use. In addition, runoff yield changed to be much quick and more sensitive to precipitation, along with the land cover conversion from forest to urban areas or other vegetation types. The impact of land use change on runoff was more distinctive when the precipitation was larger.

Finally, it can be concluded that the runoff change was affected by many factors, and the contribution ratio of each factor was different. Climate change and human activities (especially the land use change) were the two dominant drivers which contributed about $40 \% \sim 50 \%$ each to the runoff change. Particularly the land use change, whose impact on the runoff change in flood season under large precipitation, should not be neglected. The role played by climate change and human activities including land use change should be considered, respectively, in the analysis of variability and availability of water resources, and then reasonable measures and policies should be taken.

\section{Conclusions}

Based on land use maps of two time periods in the Dongjiang basin, this study identified the quantitative effects of land use and climate change on the runoff, which revealed some 


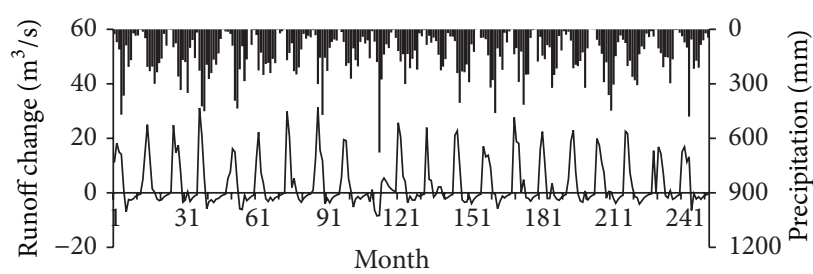

(a) Shuntian

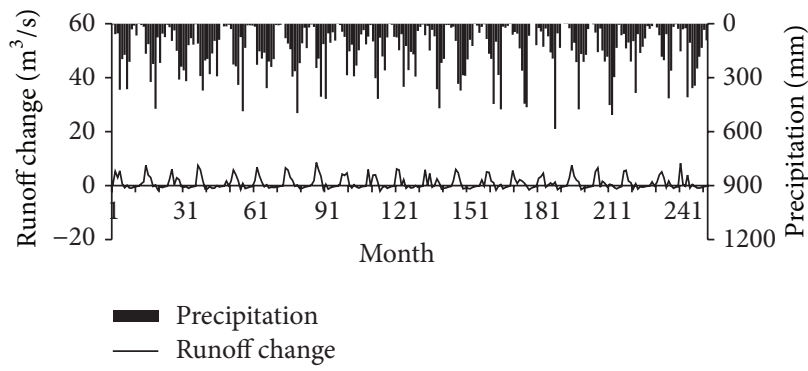

(c) Jiuzhou

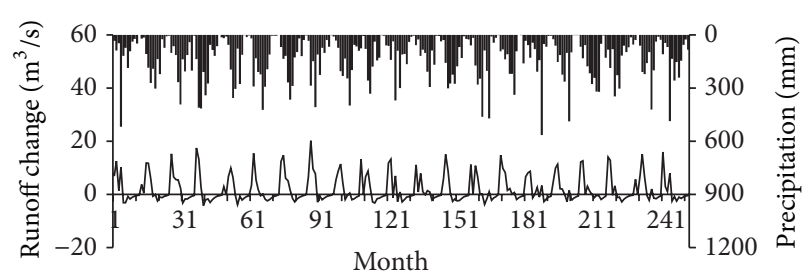

(b) Lantang

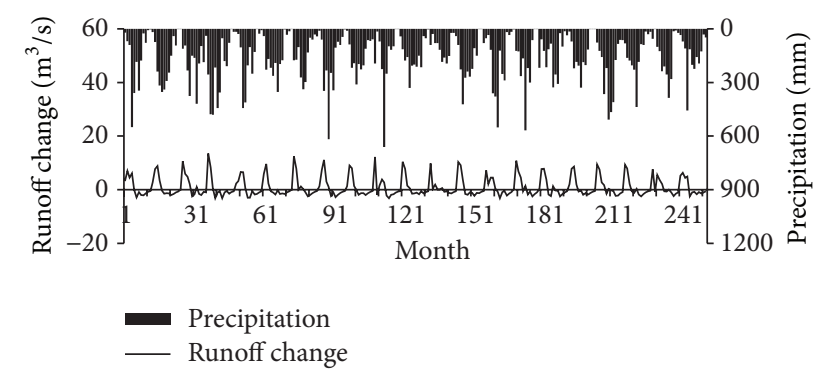

(d) Yuecheng

Figure 11: Processes of the simulated monthly runoffs change in the four sub-basins due to land use change from 1980 to 2000.

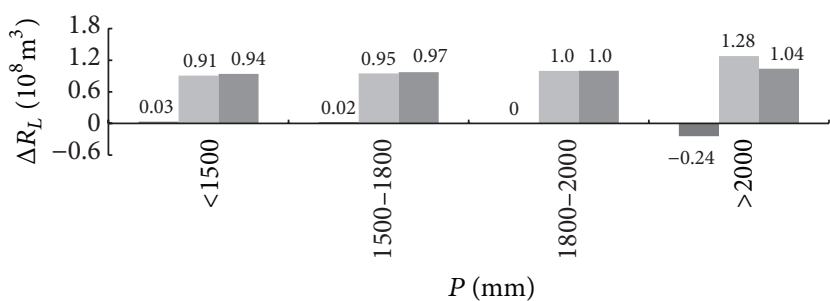

(a) Shuntian

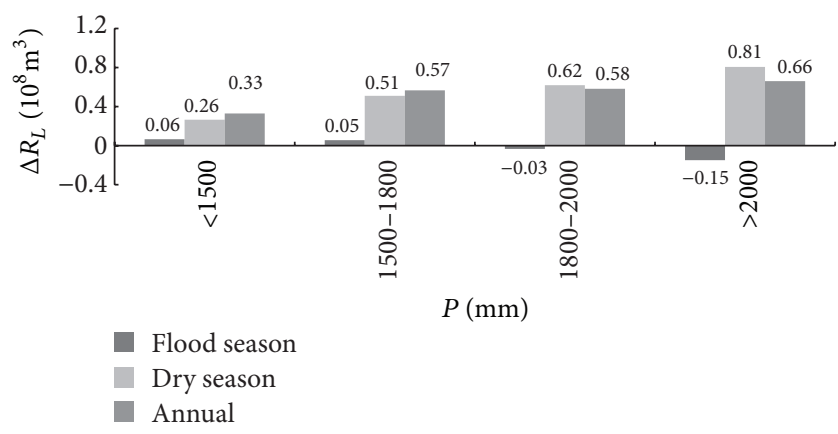

(c) Lantang

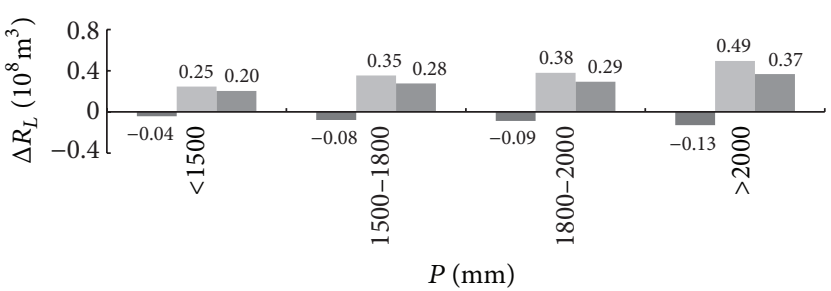

(b) Yuecheng

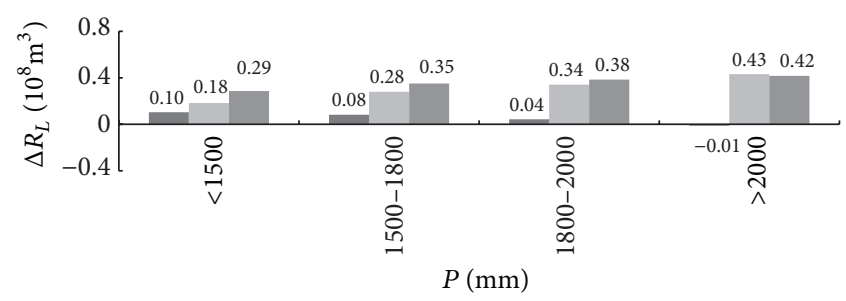

Flood season
Dry season
Annual

(d) Jiuzhou

FIGURE 12: Average annual runoff change due to land use change under different precipitation classes in the four sub-basins.

interesting results with the application of the SCS monthly model.

(1) The climate experienced significant changes in the basin over the past 50 years, and the changes were detected using the Mann-Kendall test method with the results of nonsignificant increase in precipitation, significant increase in temperature while decrease in evaporation and sunlight.

(2) Land use has experienced a significant change since the 1980s in the Dongjiang basin with the characteristic of spatial distribution for the $\mathrm{CN}$ value under three AMC scenarios in two periods. The average value of $\mathrm{CN}$ increased and the $\mathrm{CN}$ value varied in each sub-basin due to different land use patterns. In particular, expansion of urban area in the south part of the study area (downstream) and deforestation in the whole area provided contributory factors that affected hydrological processes and subsequently increased runoff.

(3) The SCS monthly model performed well in the four sub-basins of the Dongjiang basin, and the results showed that the runoff change in each sub-basin during two time periods was different. The runoff change in Yuecheng subbasin was less than that of Shuntian sub-basin and Lantang sub-basin, which was in good correlation to the variation 
TABLE 7: Simulated runoff yielded by similar amount of precipitations in the three sub-basins.

\begin{tabular}{|c|c|c|c|c|c|}
\hline \multirow{2}{*}{ Subbasins } & \multirow{2}{*}{ Year } & \multicolumn{3}{|c|}{ Precipitation $(\mathrm{mm})$} & \multirow{2}{*}{ Simulated runoff $\left(10^{8} \mathrm{~m}^{3}\right)$} \\
\hline & & Annual & Flood season & Percentage of flood season (\%) & \\
\hline \multirow{8}{*}{ Shuntian } & 2004 & 1274 & 1108.10 & 86.57 & 7.56 \\
\hline & 1999 & 1279 & 1107.50 & 87.00 & 8.41 \\
\hline & 2002 & 1421 & 1079.61 & 76.00 & 8.12 \\
\hline & 2003 & 1425 & 1256.16 & 88.17 & 9.80 \\
\hline & $1985^{*}$ & 1639 & 1217.40 & 74.27 & 11.83 \\
\hline & $1987^{*}$ & 1643 & 1185.57 & 72.14 & 13.15 \\
\hline & 1982 & 1811 & 1396.43 & 77.11 & 13.04 \\
\hline & 1984 & 1813 & 1592.17 & 87.83 & 14.70 \\
\hline \multirow{2}{*}{ Lantang } & 1986 & 1628 & 1259.60 & 77.39 & 7.96 \\
\hline & 1998 & 1631 & 1148.10 & 70.39 & 8.77 \\
\hline \multirow{4}{*}{ Jiuzhou } & 1981 & 1754 & 1427.00 & 81.35 & 4.00 \\
\hline & 1982 & 1752 & 1398.10 & 79.79 & 3.48 \\
\hline & 1984 & 1577 & 1498.50 & 95.02 & 3.87 \\
\hline & 1989 & 1575 & 1316.70 & 83.61 & 3.51 \\
\hline
\end{tabular}

Annual precipitation for Yuecheng subbasin varies greatly all the years as compared with other sub-basins, and no similar amount of precipitations can be found in different years. The impact of inner-annual distribution of precipitation on the variation of runoff in Yuecheng subbasin was neglected.

scope of the $\mathrm{CN}$ value. The more land use changed, the greater the $\mathrm{CN}$ value changed, which resulted in the greater variation of the runoff under the same climatic condition.

(4) The separated quantitative effect of land use and climate change on the runoff showed that climate change and human activities (including land use) contributed half and half, respectively, to runoff change. While land use change independently contributed $20 \%$ 30\% to the total runoff change. Moreover, the effect of land use on runoff change was in different level under different amounts of precipitation. The effect of climate change on runoff change had a different inner-annual distribution even under a same amount of annual precipitation.

Further research is required to acquire the regional future climate scenarios coupled with the hydrological model of a basin scale under GCMs (general circulation models) with the downscaling technique, so as to further quantify the relations between runoff and climatic variables. In addition, the space-time distribution of floods and droughts resulted from the runoff change should also be studied to provide scientific framework for basin-scale water resources management.

\section{Acknowledgments}

The research is financially supported by the National Natural Science Foundation of China (Grant no. 51210013), the Public Welfare Project of Ministry of Water Resources (Grant no. 201301071-02, 201301002-02), the project from Guangdong Science and Technology Department (Grant no. 2010B050300010), the project from Guangdong Water Resources Department (Grant no. 2009-39), Key Project of Chinese National Programs for Fundamental Research and Development (973 program) (Grant no. 2013CB036406, 2010CB951102), and the Pearl-River-New-Star of Science and Technology supported by Guangzhou City (Grant no. 2011J2200051).

\section{References}

[1] A. Bronstert, D. Niehoff, and G. Brger, "Effects of climate and land-use change on storm runoff generation: present knowledge and modelling capabilities," Hydrological Processes, vol. 16, no. 2, pp. 509-529, 2002.

[2] D. Legesse, C. Vallet-Coulomb, and F. Gasse, "Hydrological response of a catchment to climate and land use changes in Tropical Africa: case study south central Ethiopia," Journal of Hydrology, vol. 275, no. 1-2, pp. 67-85, 2003.

[3] B. Zimmermann, H. Elsenbeer, and J. M. De Moraes, "The influence of land-use changes on soil hydraulic properties: implications for runoff generation," Forest Ecology and Management, vol. 222, no. 1-3, pp. 29-38, 2006.

[4] D. Mao and K. A. Cherkauer, "Impacts of land-use change on hydrologic responses in the Great Lakes region," Journal of Hydrology, vol. 374, no. 1-2, pp. 71-82, 2009.

[5] N. A. Adnan and P. M. Atkinson, "Exploring the impact of climate and land use changes on streamflow trends in a monsoon catchment," International Journal of Climatology, vol. 31, no. 6, pp. 815-831, 2011.

[6] T. Jiang, Y. D. Chen, C.-Y. Xu, X. Chen, X. Chen, and V. P. Singh, "Comparison of hydrological impacts of climate change simulated by six hydrological models in the Dongjiang Basin, South China," Journal of Hydrology, vol. 336, no. 3-4, pp. 316333, 2007.

[7] G. B. Fu, J. J. Yu, X. B. Yu et al., “Temporal variation of extreme rainfall events in China, 1961-2009," Journal of Hydrology, vol. 487, pp. 48-59, 2013.

[8] G. A. Meehl, F. Zwiers, J. Evans, T. Knutson, L. Mearns, and P. Whetton, "Trends in extreme weather and climate events: issues related to modeling extremes in projections of future climate 
change," Bulletin of the American Meteorological Society, vol. 81, no. 3, pp. 427-436, 2000.

[9] S. Wang, S. Kang, L. Zhang, and F. Li, "Modelling hydrological response to different land-use and climate change scenarios in the Zamu River basin of northwest China," Hydrological Processes, vol. 22, no. 14, pp. 2502-2510, 2008.

[10] M. Verbunt, M. Groot Zwaaftink, and J. Gurtz, “The hydrologic impact of land cover changes and hydropower stations in the Alpine Rhine basin," Ecological Modelling, vol. 187, no. 1, pp. 7184, 2005.

[11] M. D. Tomer and K. E. Schilling, "A simple approach to distinguish land-use and climate-change effects on watershed hydrology," Journal of Hydrology, vol. 376, no. 1-2, pp. 24-33, 2009.

[12] E.-S. Chung, K. Park, and K. S. Lee, "The relative impacts of climate change and urbanization on the hydrological response of a Korean urban watershed," Hydrological Processes, vol. 25, no. 4, pp. 544-560, 2011.

[13] S. Piao, P. Ciais, Y. Huang et al., "The impacts of climate change on water resources and agriculture in China," Nature, vol. 467, no. 7311, pp. 43-51, 2010.

[14] P. Zhai, X. Zhang, H. Wan, and X. Pan, "Trends in total precipitation and frequency of daily precipitation extremes over China," Journal of Climate, vol. 18, no. 7, pp. 1096-1108, 2005.

[15] Y. Q. Chen, Q. Zhang, X. H. Chen, and P. Wang, "Multi-scale variability of runoff changes in the Pearl River basin, China," Quaternary International, vol. 226, pp. 44-53, 2010.

[16] C. O. Wilson and Q. Weng, "Simulating the impacts of future land use and climate changes on surface water quality in the Des Plaines River watershed, Chicago Metropolitan Statistical Area, Illinois," Science of the Total Environment, vol. 409, no. 20, pp. 4387-4405, 2011.

[17] L. Cuo, T. K. Beyene, N. Voisin et al., "Effects of mid-twentyfirst century climate and land cover change on the hydrology of the Puget Sound basin, Washington," Hydrological Processes, vol. 25, no. 11, pp. 1729-1753, 2011.

[18] J. I. López-Moreno, S. M. Vicente-Serrano, E. Moran-Tejeda, J. Zabalza, J. Lorenzo-Lacruz, and J. M. García-Ruiz, "Impact of climate evolution and land use changes on water yield in the ebro basin," Hydrology and Earth System Sciences, vol. 15, no. 1, pp. 311-322, 2011.

[19] L. M. Mango, A. M. Melesse, M. E. McClain, D. Gann, and S. G. Setegn, "Land use and climate change impacts on the hydrology of the upper Mara River Basin, Kenya: results of a modeling study to support better resource management," Hydrology and Earth System Sciences, vol. 15, no. 7, pp. 2245-2258, 2011.

[20] J. C. I. Dooge, M. Bruen, and B. Parmentier, "A simple model for estimating the sensitivity of runoff to long-term changes in precipitation without a change in vegetation," Advances in Water Resources, vol. 23, no. 2, pp. 153-163, 1999.

[21] R. D. Koster and M. J. Suarez, "A simple framework for examining the interannual variability of land surface moisture fluxes," Journal of Climate, vol. 12, no. 7, pp. 1911-1917, 1999.

[22] P. C. D. Milly and K. A. Dunne, "Macro-scale water fluxes: water and energy supply control of their inter-annual variability," Water Resources Research, vol. 38, p. 1206, 2002.

[23] X. C. Ye, Q. Zhang, and J. Liu, "Impact of climate change and human activities on runoff of Poyang Lake Catchment," Journal of Glaciology and Geocryology, vol. 31, no. 5, pp. 835-842, 2009 (Chinese).
[24] X. Ma, J. Xu, and M. van Noordwijk, "Sensitivity of streamflow from a Himalayan catchment to plausible changes in land cover and climate," Hydrological Processes, vol. 24, no. 11, pp. 13791390, 2010.

[25] X. Hao, Y. Chen, C. Xu, and W. Li, "Impacts of climate change and human activities on the surface runoff in the Tarim River Basin over the last fifty years," Water Resources Management, vol. 22, no. 9, pp. 1159-1171, 2008.

[26] J. Wang, Y. Hong, J. Gourley, P. Adhikari, L. Li, and F. Su, "Quantitative assessment of climate change and human impacts on long-term hydrologic response: a case study in a sub-basin of the Yellow River, China," International Journal of Climatology, vol. 30, no. 14, pp. 2130-2137, 2010.

[27] Z. Li, W.-Z. Liu, X.-C. Zhang, and F.-L. Zheng, "Impacts of land use change and climate variability on hydrology in an agricultural catchment on the Loess Plateau of China," Journal of Hydrology, vol. 377, no. 1-2, pp. 35-42, 2009.

[28] G. Wang, J. Xia, and J. Che, "Quantification of effects of climate variations and human activities on runoff by a monthly water balance model: a case study of the Chaobai River basin in northern China," Water Resources Research, vol. 45, no. 7, Article ID W00A11, 2009.

[29] J. Fan, F. Tian, Y. Yang, S. Han, and G. Qiu, "Quantifying the magnitude of the impact of climate change and human activity on runoff decline in Mian River Basin, China," Water Science and Technology, vol. 62, no. 4, pp. 783-791, 2010.

[30] D. Liu, X. Chen, Y. Lian, and Z. Lou, "Impacts of climate change and human activities on surface runoff in the Dongjiang River basin of China," Hydrological Processes, vol. 24, no. 11, pp. 14871495, 2010.

[31] K. Lin, S. Guo, W. Zhang, and P. Liu, "A new baseflow separation method based on analytical solutions of the Horton infiltration capacity curve," Hydrological Processes, vol. 21, no. 13, pp. 17191736, 2007.

[32] K. Lin, Q. Zhang, and X. Chen, "An evaluation of impacts of DEM resolution and parameter correlation on TOPMODEL modeling uncertainty," Journal of Hydrology, vol. 394, no. 3-4, pp. 370-383, 2010.

[33] Y. Hundecha and A. Bárdossy, "Modeling of the effect of land use changes on the runoff generation of a river basin through parameter regionalization of a watershed model," Journal of Hydrology, vol. 292, no. 1-4, pp. 281-295, 2004.

[34] K. Y. Li, M. T. Coe, N. Ramankutty, and R. D. Jong, "Modeling the hydrological impact of land-use change in West Africa," Journal of Hydrology, vol. 337, no. 3-4, pp. 258-268, 2007.

[35] G. Parkin, G. O’Donnell, J. Ewen, J. C. Bathurst, P. E. O’Connell, and J. Lavabre, "Validation of catchment models for predicting land-use and climate change impacts. 2. Case study for a Mediterranean catchment," Journal of Hydrology, vol. 175, no. 1-4, pp. 595-613, 1996.

[36] J. K. Lørup, J. C. Refsgaard, and D. Mazvimavi, "Assessing the effect of land use change on catchment runoff by combined use of statistical tests and hydrological modelling: case studies from Zimbabwe," Journal of Hydrology, vol. 205, no. 3-4, pp. 147-163, 1998.

[37] D. Niehoff, U. Fritsch, and A. Bronstert, "Land-use impacts on storm-runoff generation: scenarios of land-use change and simulation of hydrological response in a meso-scale catchment in SW-Germany," Journal of Hydrology, vol. 267, no. 1-2, pp. 8093, 2002.

[38] B. Troy, C. Sarron, J. M. Fritsch, and D. Rollin, "Assessment of the impacts of land use changes on the hydrological regime of a 
small rural catchment in South Africa," Physics and Chemistry of the Earth, vol. 32, no. 15-18, pp. 984-994, 2007.

[39] H. Chen, S. Guo, C.-Y. Xu, and V. P. Singh, "Historical temporal trends of hydro-climatic variables and runoff response to climate variability and their relevance in water resource management in the Hanjiang basin," Journal of Hydrology, vol. 344, no. 3-4, pp. 171-184, 2007.

[40] D. H. Burn, "Climatic influences on streamflow timing in the headwaters of the Mackenzie River Basin," Journal of Hydrology, vol. 352, no. 1-2, pp. 225-238, 2008.

[41] H. B. Mann, "Nonparametric tests against trend," Econometrica, vol. 13, no. 7, pp. 245-259, 1945.

[42] M. G. Kendall, Rank Correlation Methods, Griffin, London, UK, 1975.

[43] J. M. Mitchell, B. Dzerdzeevskii, H. Flohn et al., "Climate change," WMO Technical Note 79, World Meteorological Organization, 1966.

[44] E. Kahya and S. Kalayci, "Trend analysis of streamflow in Turkey," Journal of Hydrology, vol. 289, no. 1-4, pp. 128-144, 2004.

[45] Z. X. Xu, K. Takeuchi, H. Ishidaira, and J. Y. Li, "Long-term trend analysis for precipitation in Asian Pacific FRIEND river basins," Hydrological Processes, vol. 19, no. 18, pp. 3517-3532, 2005.

[46] R. Modarres and V. de Paulo Rodrigues da Silva, "Rainfall trends in arid and semi-arid regions of Iran," Journal of Arid Environments, vol. 70, no. 2, pp. 344-355, 2007.

[47] F.-W. Gerstengarbe and P. C. Werner, "Estimation of the beginning and end of recurrent events within a climate regime," Climate Research, vol. 11, no. 2, pp. 97-107, 1999.

[48] T. Jiang and Q. Zhang, "Climatic changes driving on floods in the Yangtze Delta, China during 1000-2002," European Journal of Geography, Cybergeo, vol. 296, pp. 1-21, 2004.

[49] M. Ç. Karabörk, "Trends in drought patterns of Turkey," Journal of Environmental Engineering and Science, vol. 6, no. 1, pp. 4552, 2007.

[50] D. Ramakrishnan, A. Bandyopadhyay, and K. N. Kusuma, "SCS$\mathrm{CN}$ and GIS-based approach for identifying potential water harvesting sites in the Kali Watershed, Mahi River Basin, India," Journal of Earth System Science, vol. 118, no. 4, pp. 355-368, 2009.

[51] R. K. Sahu, S. K. Mishra, and T. I. Eldho, "Comparative evaluation of SCS-CN-inspired models in applications to classified datasets," Agricultural Water Management, vol. 97, no. 5, pp. 749-756, 2010.

[52] D. G. Durbude, M. K. Jain, and S. K. Mishra, "Long-term hydrologic simulation using SCS-CN-based improved soil moisture accounting procedure," Hydrological Processes, vol. 25, no. 4, pp. 561-579, 2011.

[53] L. H. Xiong and S. L. Guo, Distributed Hydrological Model, China Water Power Press, 2004.

[54] X. H. Chen and Z. L. Wang, "Land use change and its impact on water resources in east river basin, south China," Journal of Beijing Normal University, vol. 46, no. 3, pp. 311-316, 2010 (Chinese).

[55] J. E. Nash and J. V. Sutcliffe, "River flow forecasting through conceptual models part I-a discussion of principles," Journal of Hydrology, vol. 10, no. 3, pp. 282-290, 1970. 


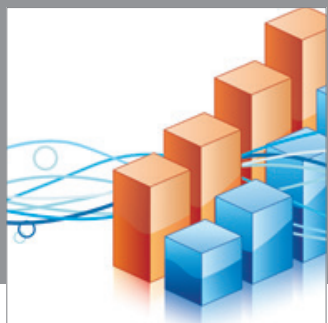

Advances in

Operations Research

mansans

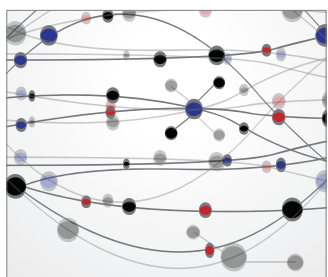

The Scientific World Journal
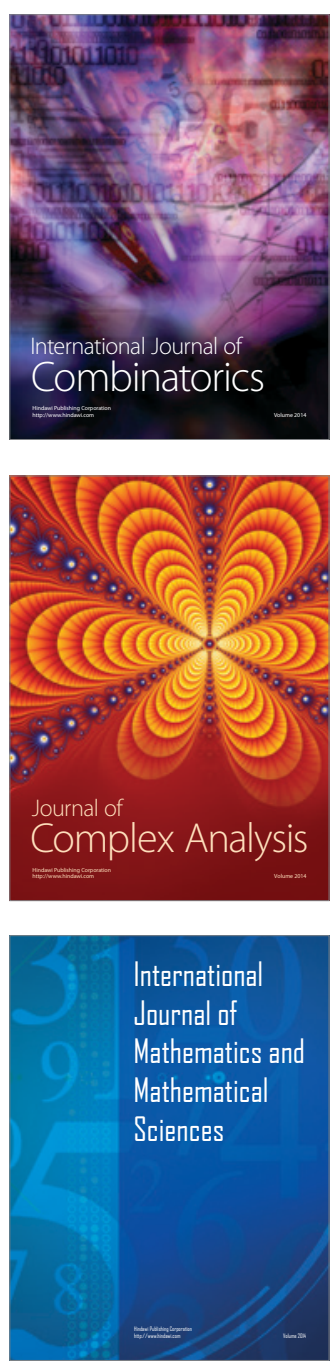
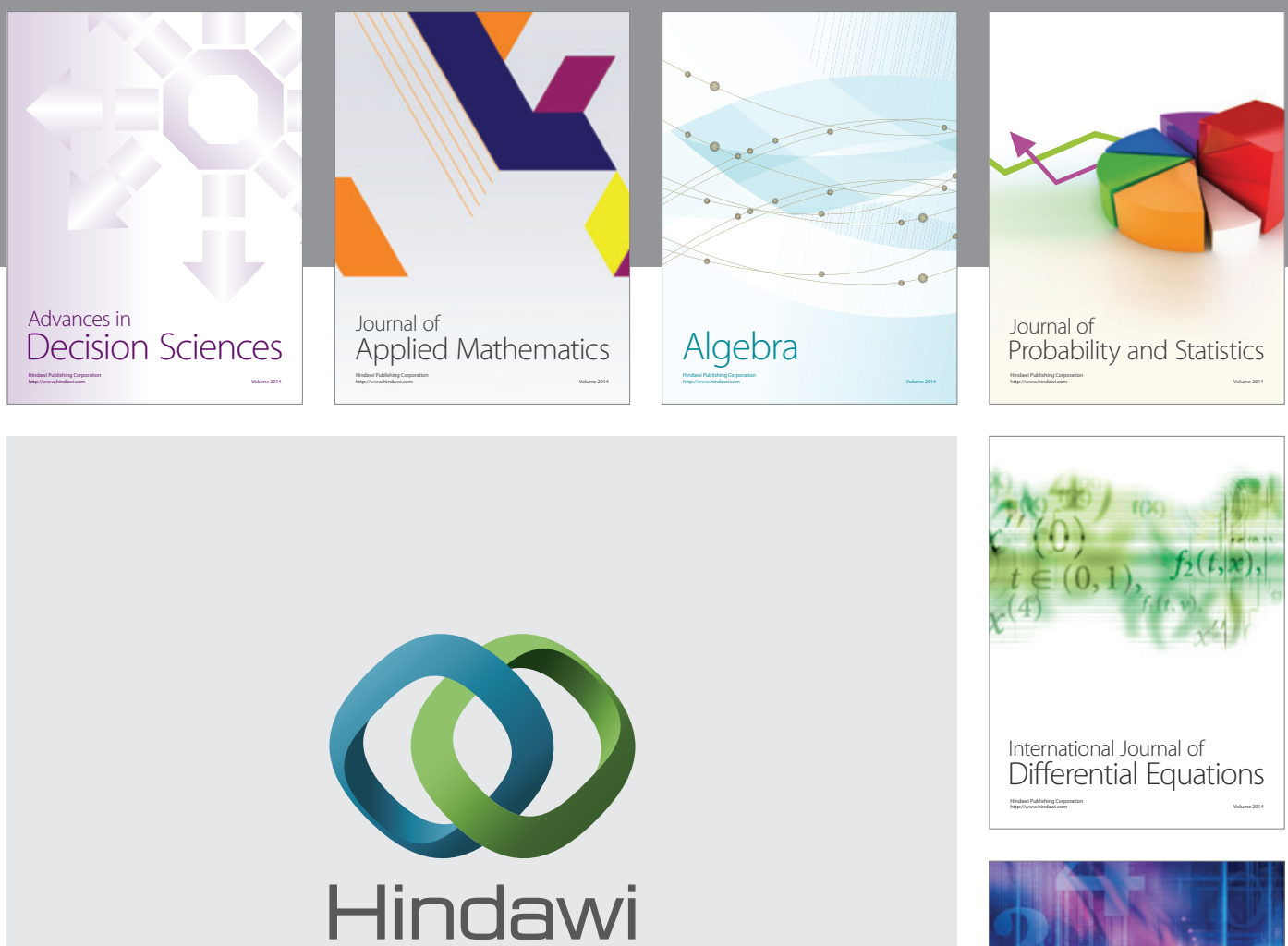

Submit your manuscripts at http://www.hindawi.com
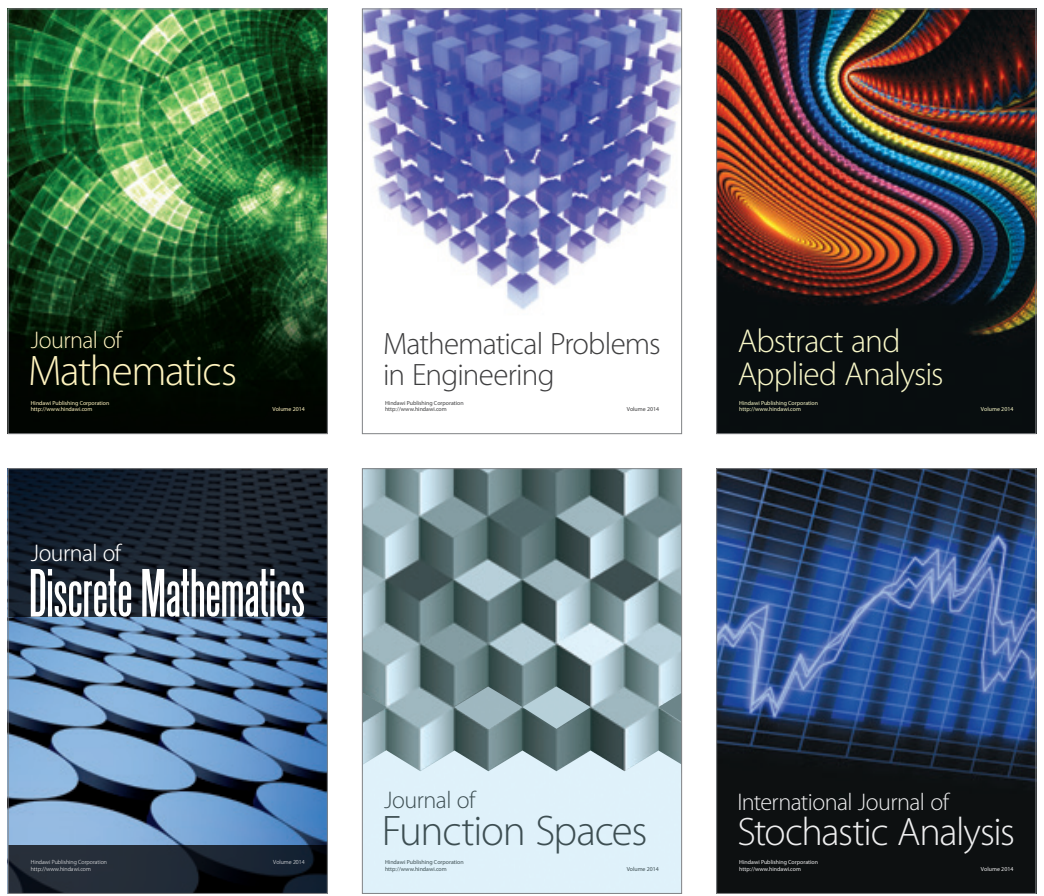

Journal of

Function Spaces

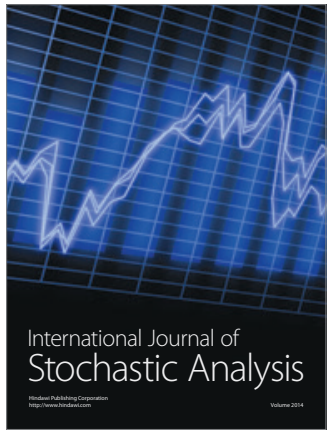

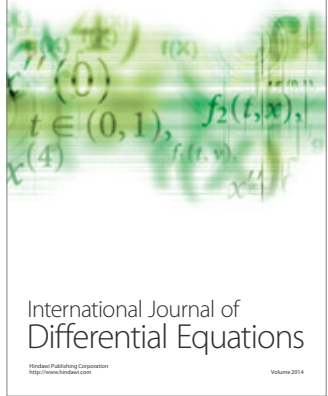
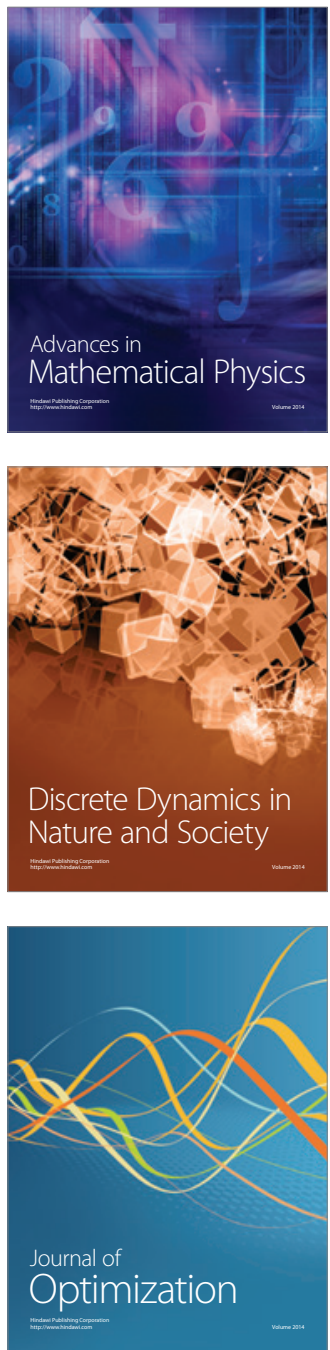